\title{
ZnO Nanorod Arrays Fabricated by Hydrothermal Method Using Different Thicknesses of Seed Layers for Applications in Hybrid Photovoltaic Cells
}

\author{
Witchaya Arpavate, Surawut Chuangchote, ${ }^{1,2^{*}}$ Navadol Laosiripojana, ${ }^{1,2}$ \\ Jatuphorn Wootthikanokkhan, ${ }^{3,4}$ and Takashi Sagawa ${ }^{5}$ \\ Faculty of Engineering, Rajamangala University of Technology Phra Nakhon, \\ 1381 Pracharat1 Rd., Bangsue, Bangkok 10800, Thailand \\ ${ }^{1}$ The Joint Graduate School of Energy and Environment, King Mongkut's University of Technology Thonburi, \\ 126 Prachauthit Rd., Bangmod, Tungkru, Bangkok 10140, Thailand \\ ${ }^{2}$ Center for Energy Technology and Environment, Ministry of Education, Thailand \\ ${ }^{3}$ Division of Materials Technology, School of Energy, Environment and Materials, \\ King Mongkut's University of Technology Thonburi, 126 Prachauthit Rd., \\ Bangmod, Tungkru, Bangkok 10140, Thailand \\ ${ }^{4}$ Nanotec-KMUTT Center of Excellence on Hybrid Nanomaterials for Alternative Energy, \\ King Mongkut's University of Technology Thonburi, 126 Prachauthit Rd., \\ Bangmod, Tungkru, Bangkok 10140, Thailand \\ ${ }^{5}$ Graduate School of Energy Science, Kyoto University, Yoshida-honmachi, \\ Sakyo-ku, Kyoto 606-8501, Japan
}

(Received August 31, 2015; accepted February 4, 2016)

Keywords: zinc oxide nanorods, hydrothermal method, seed layer, hybrid photovoltaic cell

$\mathrm{ZnO}$ nanorod arrays have been synthesized on seed-coated indium tin oxide (ITO) substrates by a hydrothermal method from different thicknesses of seed layers. The $\mathrm{ZnO}$ nanorods obtained were investigated by scanning electron microscopy (SEM) to study the influence of different seed layer thicknesses on the orientation of the nanorods. The diameter of $\mathrm{ZnO}$ nanorods increased with increasing seed layer thickness. An X-ray diffractometer was used to verify the formation of $\mathrm{ZnO}$ nanorods on ITO. Well-aligned $\mathrm{ZnO}$ nanorods from various seed layer thicknesses were used as electron transporting layers in hybrid photovoltaic cells. Photovoltaic properties and power conversion efficiency (PCE) of devices made of $\mathrm{ZnO}$ nanorod arrays were investigated. PCE of up to $1.02 \%$ can be achieved from a cell made of $\mathrm{ZnO}$ nanorods grown on two suitable seed layers.

\section{Introduction}

Currently, researchers in solar energy have given much attention to solving increasing demands for energy. The conversion of solar energy into electricity is clean, and the sun is renewable resource. Silicon solar cells dominate the photovoltaic market and have been reported to have power conversion efficiencies (PCEs) of up to $25 \%$. Although the efficiency of silicon-based solar cells is high, manufacturing is still expensive. The development of solar cells with reduced production costs has led to solar cells made of organic materials. Organic photovoltaic cells

"Corresponding author: e-mail: surawut.chu@kmutt.ac.th 
are of great interest owing to the ability to process them in solution, low manufacturing costs, and light weight. ${ }^{(1,2)}$ In the organic system, an electron donor has the role of absorbing photons and generating excitons. When excitons diffuse to the interface between two components and dissociate, the electron acceptor receives electrons and transfers them to an electrode, while the electron donor carries holes to another electrode. The absorber layer in devices is composed of a conjugated polymer and a soluble fullerene. Many reports of organic photovoltaic cells are focused on poly(3-hexylthiophene) (P3HT) as a donor and 6,6-phenyl- $\mathrm{C}_{61}$-butyric acid methylester (PCBM) as an acceptor. However, the PCEs of organic photovoltaic cells are still very low, because of low stability and low mobility associated with transferring excited electrons or holes. Therefore, hybrid photovoltaic cells, which combine organic and inorganic materials, have been studied to solve the problem of low charge mobility and to improve efficiency by using inorganic nanostructures as electron collecting layers. ${ }^{(3,4)}$

Among several kinds of inorganic semiconductors, metal oxides have been extensively used in hybrid photovoltaic cells because they have high conductivities and can be prepared as different nanostructures such as nanorods, nanotubes, and nanoparticles. Zinc oxide $(\mathrm{ZnO})$ is an attractive metal oxide that can be used in photovoltaic devices because of its wide band gap (3.37 eV), high electron transport characteristics, and excellent chemical and thermal stability. It can be easily formed as nanorods, which have a direct pathway to transport charges. ${ }^{(4,5)} \mathrm{ZnO}$ nanorod arrays have been fabricated by various preparation methods such as vapor-liquid-solid techniques, ${ }^{(6)}$ chemical vapor deposition, ${ }^{(7)}$ electrochemical deposition, ${ }^{(8)}$ and hydrothermal methods. ${ }^{(5,9,10)}$ A hydrothermal method is a simple and cheap technique when compared with the others because it requires no vacuum, no expensive equipment, and no special substrates..$^{(11)}$

There are many studies about controlling the parameters such as reaction time, ${ }^{(12)}$ temperature, ${ }^{(13)}$ concentration of precursor, ${ }^{(14)}$ and seed layer thicknesses, ${ }^{(15,16)}$ which affect the growth of $\mathrm{ZnO}$ nanorod arrays by hydrothermal methods. However, there are no reports of hybrid photovoltaic cells made of $\mathrm{ZnO}$ nanorods fabricated from seed layers with different thicknesses.

In this work, $\mathrm{ZnO}$ nanorod arrays were synthesized under different conditions of seed layer thickness. The morphology of the grown $\mathrm{ZnO}$ nanorod arrays was investigated, and the applications of $\mathrm{ZnO}$ nanorod arrays to hybrid photovoltaic cells were studied.

\section{Materials and Methods}

\subsection{Preparation of $\mathrm{ZnO}$ nanorod arrays}

$\mathrm{ZnO}$ nanorod arrays were prepared on indium tin oxide (ITO) substrates, which were cleaned ultrasonically in deionized water, ethanol, and acetone. Zinc acetate in ethanol $(0.01 \mathrm{M})$ was spincoated on the cleaned ITO substrate. The seed-coated substrate was annealed at $260{ }^{\circ} \mathrm{C}$ for $5 \mathrm{~h}$ in the air to form crystal seeds on the substrate. $\mathrm{ZnO}$ nanorods were grown perpendicularly on the seed layer by immersing $\mathrm{ZnO}$-coated glass substrates into $0.04 \mathrm{M}$ of zinc nitrate and $0.8 \mathrm{M}$ of sodium hydroxide at $110{ }^{\circ} \mathrm{C}$ for $20 \mathrm{~min}$. After immersion, the ITO substrates with aligned $\mathrm{ZnO}$ nanorod arrays were washed with deionized water to remove the residual material and dried in the air. 


\subsection{Fabrication of hybrid photovoltaic cell}

A mixture of P3HT and PCBM $(1: 0.8 \mathrm{w} / \mathrm{w})$ in dichlorobenzene $(500 \mu \mathrm{l})$ was coated on the $\mathrm{ZnO}$ nanorod arrays. Subsequently, the sample was thermally annealed at $165{ }^{\circ} \mathrm{C}$ for $20 \mathrm{~min}$ in a dry environment. After the heat treatment, tungsten trioxide $\left(\mathrm{WO}_{3}\right)$ was coated on the blended polymers using a solution process. Finally, a Ag layer, which served as an anode, was deposited on the fabricated structure by thermal evaporation.

\subsection{Characterization}

The morphology and structure of the nanorod arrays were characterized by scanning electron microscopy (SEM, JEOL JSM-6610LV) with an accelerating voltage of $20 \mathrm{kV}$. The crystalline structure was characterized by X-ray diffraction (XRD, Bruker D8 Advance). Photocurrent density-voltage $(J-V)$ curves were measured under simulated solar light (AM 1.5, $\left.100 \mathrm{~mW} / \mathrm{cm}^{2}\right)$.

\section{Results and Discussion}

$\mathrm{ZnO}$ nanorod arrays were grown by the hydrothermal method at a temperature of $110{ }^{\circ} \mathrm{C}$ for 20 min. The morphology of $\mathrm{ZnO}$ nanorod arrays deposited on ITO substrates that were coated with seed layers of different thicknesses was investigated by SEM. Figure 1(a) shows ZnO nanorod arrays grown on one layer of seed thickness; $\mathrm{ZnO}$ nanorods have high density and small diameter $(\sim 350 \mathrm{~nm})$. The growth of $\mathrm{ZnO}$ nanorod arrays on two seed layers is shown in Fig. 1(b); the $\mathrm{ZnO}$ nanorods have the Wurtzite hexagonal structure and the rod diameter increased $(\sim 600 \mathrm{~nm})$. As can be seen in Fig. 1(c), the diameter of $\mathrm{ZnO}$ nanorod arrays grown on three seed layers was the largest $(\sim 1$ $\mu \mathrm{m})$ and the density of the rods was low.

It was found that a thinner seed layer resulted in a higher density of $\mathrm{ZnO}$ nanorod arrays. This results from the nucleation sites on the surface of the seed layer decreasing when the thickness of the seed layers increases. Moreover, the diameter of nanorods depends on the particle size in the seed layer, because an increase in seed layer thickness affects the increase of the particle size in the seed layer. Therefore, the thickness of the seed layer plays a role in determining the diameter of $\mathrm{ZnO}$ nanorod arrays. ${ }^{(16)}$

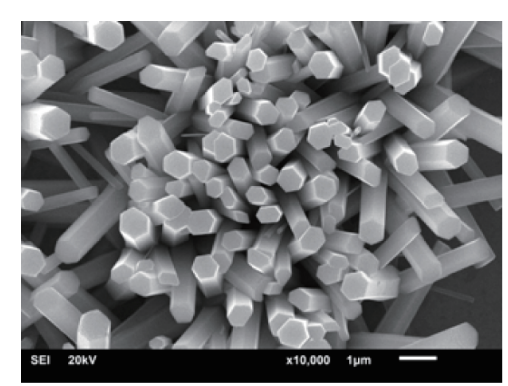

(a)

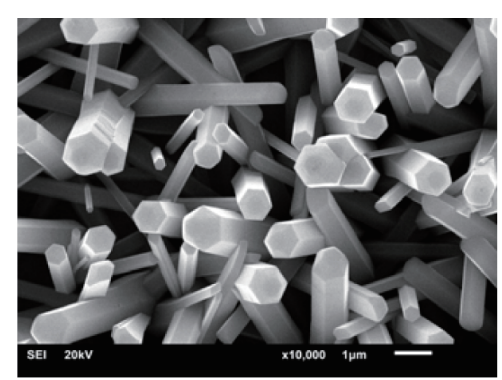

(b)

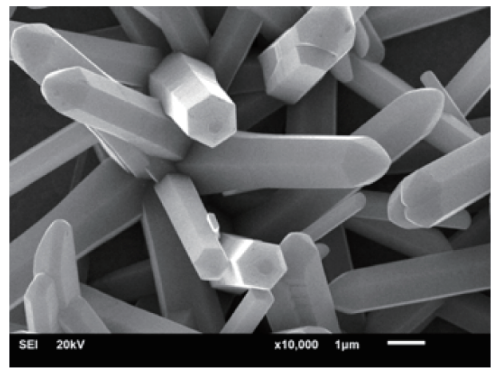

(c)

Fig. 1. SEM images of $\mathrm{ZnO}$ nanorod arrays grown on seed layers of varying thickness: (a) one, (b) two, and (c) three seed layer(s). 
The XRD pattern of a cleaned ITO substrate is shown in Fig. 2(a). Figure 2(b) shows the XRD result of the thickness of two seed layers on an ITO substrate after annealing. The XRD pattern of $\mathrm{ZnO}$ nanorod arrays grown on coated ITO with two seed layers is shown in Fig. 2(c). Many peaks in the pattern of $\mathrm{ZnO}$ nanorods on ITO are totally different from those seen as pristine ITO, which are the characteristic peaks of $\mathrm{ZnO}$.

The $\mathrm{ZnO}$ nanorod arrays with various seed layer thicknesses were applied as electron transporting layers on hybrid photovoltaic cells. The structure of a cell is ITO/ZnO nanorods/ $\mathrm{PCBM} / \mathrm{P} 3 \mathrm{HT} / \mathrm{WO}_{3} / \mathrm{Ag}$, as shown in Fig. 3. Figure 4 shows $J-V$ curves of hybrid photovoltaic cells made of $\mathrm{ZnO}$ nanorods grown on $\mathrm{ZnO}$ seeds for different seed thicknesses. Table 1 shows characteristic photovoltaic properties, i.e. short-circuit photocurrent density $\left(J_{\mathrm{sc}}\right)$, open-circuit

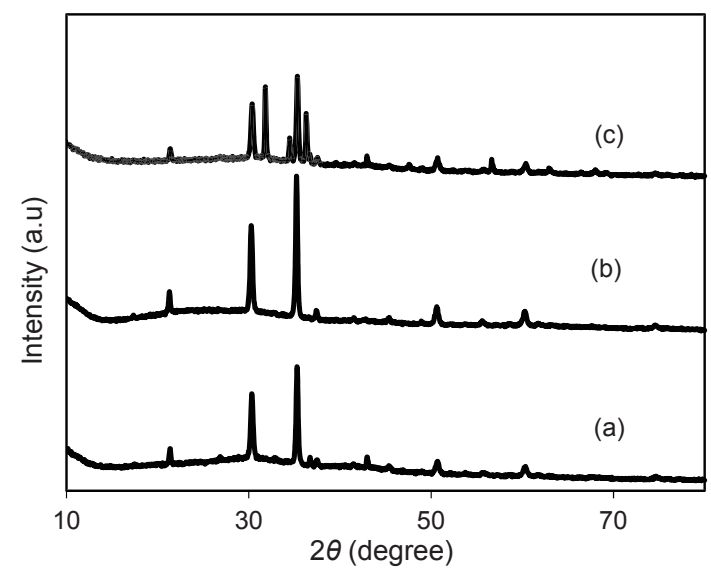

Fig. 2. XRD pattern of (a) ITO substrate, (b) ZnO seeded ITO substrate, and (c) $\mathrm{ZnO}$ nanorod arrays on ITO substrate.

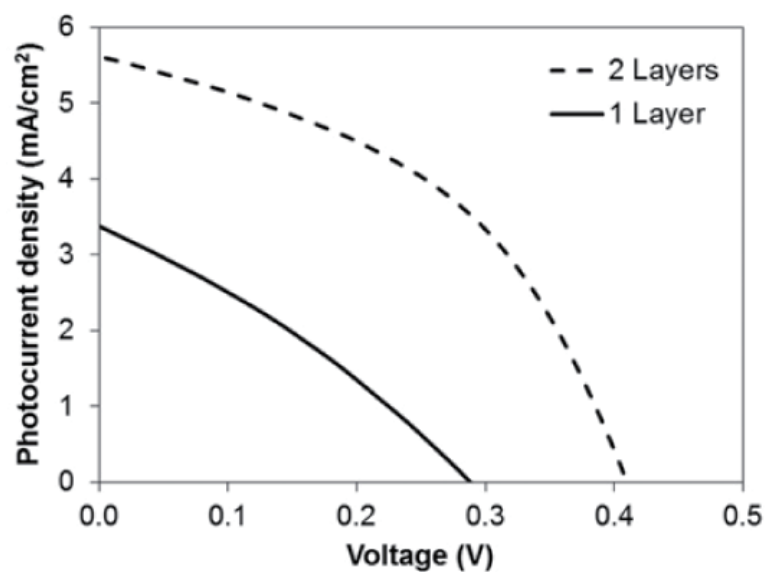

Fig. 4. $J-V$ curves of hybrid photovoltaic cells made of $\mathrm{ZnO}$ nanorods grown on $\mathrm{ZnO}$ seeds for different seed thicknesses.

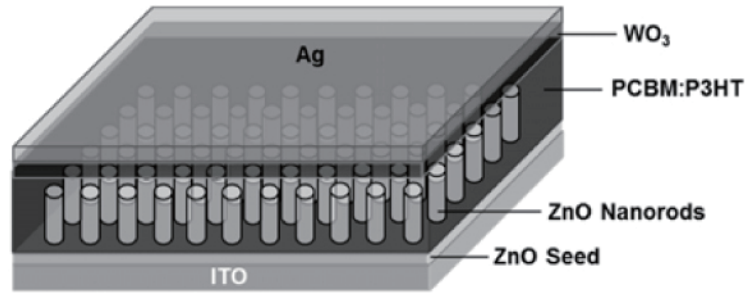

Fig. 3. Cell structure of hybrid photovoltaic cells made of $\mathrm{ZnO}$ nanorods.

Table 1

Photovoltaic characteristic properties of cells made of $\mathrm{ZnO}$ nanorods arrays grown on $\mathrm{ZnO}$ seeds with number of different seed layers.

\begin{tabular}{lcccc}
\hline Seed & $\begin{array}{c}J_{\mathrm{sc}} \\
\left(\mathrm{mA} / \mathrm{cm}^{2}\right)\end{array}$ & $V_{\text {oc }}(\mathrm{V})$ & $F F$ & $P C E(\%)$ \\
\hline 1 layer & 3.38 & 0.29 & 0.32 & 0.29 \\
2 layers & 5.62 & 0.41 & 0.44 & 1.02 \\
3 layers & $\mathrm{n} / \mathrm{a}$ & $\mathrm{n} / \mathrm{a}$ & $\mathrm{n} / \mathrm{a}$ & $\mathrm{n} / \mathrm{a}$ \\
\hline
\end{tabular}


voltage $\left(V_{\mathrm{oc}}\right)$, fill factor $(F F)$, and PCE $(P C E)$, of the cells investigated. It was observed that $\mathrm{ZnO}$ nanorods grown on $\mathrm{ZnO}$ seeds with one seed layer showed low PCE. Even if the diameter of cell was small, the density of nanorods was high, so the active PCBM:P3HT could not easily penetrate to the nanorod later. The PCE of the cells increased when the number of seed layers was increased to two. Even if the diameter of rods was larger, which reduced the surface area, the density of rods was suitable for the penetration of the active layer. Lastly, with three layers of seed, the cell short circuited, because the diameter of nanorods standing over the active layer was too large and contacted the Ag electrode. From this observation, we concluded that the suitable number of seed layers for $\mathrm{ZnO}$ seeding was two.

\section{Conclusions}

$\mathrm{ZnO}$ nanorod arrays have been synthesized on seed-coated ITO substrates using a hydrothermal method from different thicknesses of seed layers. The seed layer thicknesses influences the diameter and density of nanorods. The $\mathrm{ZnO}$ nanorods had low density and increased in diameter as seed layer thickness was increased. Well-aligned $\mathrm{ZnO}$ nanorods from the suitable seed layer thickness were used as an electron transporting layer in hybrid photovoltaic cells. A PCE of $1.02 \%$ can be achieved to from a cell made of $\mathrm{ZnO}$ nanorods grown on two seed layers.

\section{Acknowledgements}

This work was partially supported by Thailand Research Fund (TRF) (TRG5780129), the Nanotechnology Center (NANOTEC), the National Science and Technology Development Agency (NSTDA), and the Ministry of Science and Technology, Thailand, through its program of Center of Excellence Network.

\section{References}

1 M. Wright and A. Uddin: Solar Energy Mater. Solar Cells 107 (2012) 87.

2 J. H. Heo, S. H. Im, J. H. Noh, T. N. Mandal, C. S. Lim, J. A. Chang, Y. H. Lee, H. J. Kim, A. Sarkar, Md. K. Nazeeruddin, M. Grätzel, and S. I. Seok: Nat. Photonics 7 (2013) 486.

3 T. Rattanavoravipa, P. Chareonsirithavorn, T. Sagawa, and S. Yoshikawa: Solid-State Electron. 53 (2009) 176.

4 S. Chuangchote, T. Sagawa, and S. Yoshikawa: J. Mater. Res. 26 (2011) 2316.

5 J. Zhao, Z. G. Jin, X. X. Liu, and Z. F. Liu: J. Eur. Ceramic Soc. 26 (2006) 3745.

6 Q. X. Zhao, P. Klason, and M. Willander: Appl. Phys. A 88 (2007) 27.

7 J. J. Wu and S. C. Liu: J. Phys. Chem. B 106 (2002) 9546.

8 M. Chang, X. Cao, and H. Zeng: J. Phys. Chem. C 113 (2009) 15544.

9 K. Khun, Z. H. Ibupoto, M. S. AlSalhi, M. Atif, A. A. Ansari, and M. Willander: Materials 6 (2013) 4361.

10 T. P. Chen, S. J. Young, S. J. Chang, C. H. Hsiao, L. W. Ji, Y. J. Hsu, and S. L. Wu: IEEE Sens. J. 13 (2013) 2115.

11 S. N. Bai and S. C. Wu: J. Mater. Sci. Mater. Electron. 22 (2011) 339.

12 K. A. Wahid, W. Y. Lee, H. W. Lee, A. S. Teh, D. C. S. Bien, and I. A. Azid: Appl. Surf. Sci. 283 (2013) 629.

13 Z. Qin, Q. Liao, Y. Huang, L. Tang, X. Zhang, and Y. Zhang: Mater. Chem. Phys. 123 (2010) 811.

14 M. Wang, C. Xing, K. Cao, L. Meng, and J. Liu: J. Phys. Chem. Solids 75 (2014) 808.

15 S. J. Kim, H. H. Kim, J. B. Kwon, J. G. Lee, B. H. O, S. G. Lee, E. H. Lee, and S. G. Park: Microelectron. Eng. 87 (2010) 1534.

16 H. Ghayour, H. R. Rezaie, Sh. Mirdamadi, and A. A. Nourbakhsh: Vacuum 86 (2011) 101. 
About the Authors

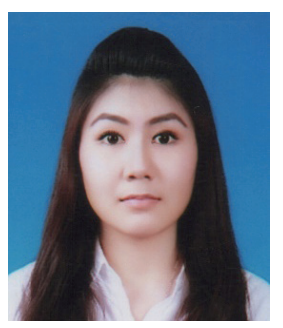

Witchaya Arpavate received her B.E. and M.E. degrees from King Mongkut's University of Technology Thonburi, Thailand, in 2012 and 2015, respectively. Since 2015, she has been a lecturer at Rajamangala University of Technology Phra Nakhon, Thailand. Her research interests are the fabrication and characterization of nanorods, fuel cells, and solar cells.

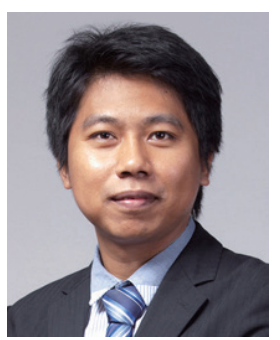

Surawut Chuangchote received his B.E. degree from Silpakorn University, Thailand, in 2004, M.S. degree from Chulalongkorn University, Thailand, in 2006, and Ph.D. from Kyoto University, Japan, in 2009. From 2009 to 2012, he was a researcher ( 6 months) and a postdoctoral research fellow ( 2 years) at Kyoto University, Japan. Since 2012, he has been a researcher at The Joint Graduate School of Energy and Environment, King Mongkut's University of Technology Thonburi, Thailand. His research interests are nanomaterial fabrications, nanomaterials for energy and environmental applications, emerging solar cells, and photocatalysts for biomass conversion.

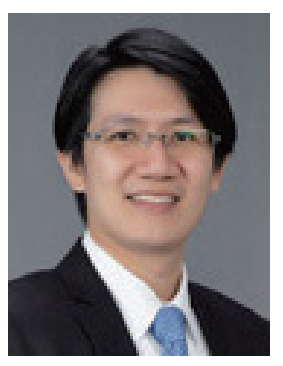

Navadol Laosiripojana received his B.E. degree from Chulalongkorn University, Thailand, in 1999, and his M.S. and Ph.D. degrees from Imperial College London, UK, in 2001 and 2003, respectively. He became a lecturer, an assistant professor, and an associate professor at The Joint Graduate School of Energy and Environment, King Mongkut's University of Technology Thonburi, Thailand, in 2003, 2005, and 2008, respectively. In 2012, he was promoted to professor at The Joint Graduate School of Energy and Environment. His research interests are biofuel production, biorefinery, hydrogen production, natural gas purification, and catalytic processes.

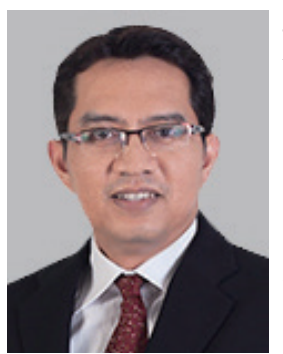

Jatuphorn Wootthikanokkhan received his B.S. degree from Mahidol University, Thailand, in 1989, and his Ph.D. degree from University of New South Wales, Australia, in 1997. He was a lecturer and an assistant professor at The School of Energy, Environment and Materials, King Mongkut's University of Technology Thonburi, Thailand, in 1997 and 2002, respectively. Since 2005, he has been an associate professor at The School of Energy, Environment and Materials. His research interests are polymer synthesis, polymer blends, modifications of natural rubber, polymer adhesives, nanomaterials, and conducting polymers for solar cells.

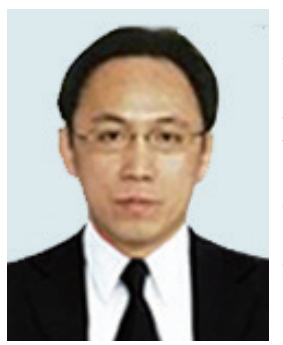

Takashi Sagawa received his B.S., M.S., and Ph.D. degrees from Kumamoto University, Japan, in 1987, 1989, and 1995, respectively. He was an assistant professor at Kumamoto University from 1990 to 2000, and Kyoto University from 2000 to 2006. From 2006 to 2012, he was an associate professor at Kyoto University. In 2012, he became a full professor at Kyoto University. His research interests are materials design of organic and inorganic composites for fundamental applications of photocatalysts, solar cells, and LEDs, in addition to spectroscopic and microscopic analyses of the designed materials. 